Review

\title{
Saporin-S6: A Useful Tool in Cancer Therapy
}

\section{Letizia Polito *, Massimo Bortolotti, Daniele Mercatelli, Maria Giulia Battelli and Andrea Bolognesi}

Department of Experimental, Diagnostic and Specialty Medicine-DIMES; Alma Mater Studiorum, University of Bologna, Via San Giacomo 14, 40126 Bologna, Italy;

E-Mails: massimo.bortolotti2@unibo.it (M.B.); daniele.mercatelli2@unibo.it (D.M.); mariagiulia.battelli@unibo.it (M.G.B.); andrea.bolognesi@unibo.it (A.B.)

* Author to whom correspondence should be addressed; E-Mail: letizia.polito@unibo.it; Tel.: +39-0512094723; Fax: +39-0512094746.

Received: 19 July 2013; in revised form: 17 September 2013 / Accepted: 22 September 2013 / Published: 7 October 2013

\begin{abstract}
Thirty years ago, the type 1 ribosome-inactivating protein (RIP) saporin-S6 (also known as saporin) was isolated from Saponaria officinalis L. seeds. Since then, the properties and mechanisms of action of saporin-S6 have been well characterized, and it has been widely employed in the construction of conjugates and immunotoxins for different purposes. These immunotoxins have shown many interesting results when used in cancer therapy, particularly in hematological tumors. The high enzymatic activity, stability and resistance to conjugation procedures and blood proteases make saporin-S6 a very useful tool in cancer therapy. High efficacy has been reported in clinical trials with saporin-S6-containing immunotoxins, at dosages that induced only mild and transient side effects, which were mainly fever, myalgias, hepatotoxicity, thrombocytopenia and vascular leak syndrome. Moreover, saporin-S6 triggers multiple cell death pathways, rendering impossible the selection of RIP-resistant mutants. In this review, some aspects of saporin-S6, such as the chemico-physical characteristics, the structural properties, its endocytosis, its intracellular routing and the pathogenetic mechanisms of the cell damage, are reported. In addition, the recent progress and developments of saporin-S6-containing immunotoxins in cancer immunotherapy are summarized, including in vitro and in vivo pre-clinical studies and clinical trials.
\end{abstract}


Keywords: saporin-S6; saporin; Saponaria officinalis; immunotoxin; immunotherapy; ribosome-inactivating proteins; monoclonal antibodies; rRNA $N$-glycosylase activity; anti-cancer therapy; hematological tumors

\section{Overview}

Saporin-S6 (also known as saporin) is a plant toxin belonging to the ribosome-inactivating protein (RIP) family, a class of toxic enzymes that is widely distributed among plant genera whose activity is classically identified as rRNA $N$-glycosylase (EC 3.2.2.22). RIPs specifically remove the A4324 adenine residue, which forms part of a tetranucleotide G(A4324)GA sequence on the ricin/sarcin region of the $28 \mathrm{~S}$ rRNA in the $60 \mathrm{~S}$ subunit of the rat ribosome, a sequence that is universally conserved among eukaryotic rRNA. Adenine removal interferes with the interaction between the ribosome and the elongation factor 2, damaging ribosomes in an irreversible manner and causing the inhibition of protein synthesis [1]. RIPs also show in vitro $N$-glycosylase activity on different substrates, such as mRNA, tRNA, DNA and poly(A) [2,3], and some RIPs have also shown activity against poly(ADP-ribosyl)ated proteins [4]. For this reason, the enzymatic activity of RIPs has been defined as polynucleotide:adenosine glycosylase (PNAG) [3].

RIPs are classified into type 1, which consist of a single-chain protein with enzymatic activity, type 2, with an enzymatic A-chain linked by a disulfide bond to a lectin B-chain that is able to bind to sugar-containing cell surface receptors, and type 3, composed of an $\mathrm{N}$-terminal catalytic domain and an extended $C$-terminal domain whose function is unknown [5]. The presence of the B-chain in type 2 RIPs allows the fast internalization of the toxin into the cell. Inside the cell, the A-B moieties are separated so that the active A-chain can enter the cytosol, where it exerts its ribotoxic action. For this reason, most type 2 RIPs are very toxic. However, a number of non-toxic type 2 RIPs were found in some plant species belonging to the Sambucus genus [6]. Despite the differences reported for animal and cell toxicity [7], RIPs often show a similar activity on ribosomes in a cell-free system [8].

RIPs have been widely studied because of their potential therapeutic application in a variety of human diseases as toxic moiety of a conjugate. The conjugation of a cytotoxic RIP to a target-specific carrier, such as a monoclonal antibody $(\mathrm{mAb})$, allows the selective killing of target cells. Conjugates containing antibodies or their fragments are referred to as immunotoxins (ITs). ITs have been obtained both by the chemical linkage of the toxic moiety to mAbs and by genetic engineering to obtain recombinant conjugates [9]. RIP-containing ITs have been included in clinical trials against various diseases, often achieving promising results, especially in the treatment of hematological neoplasms [10]. A series of ITs containing different Abs and type 1 RIPs has been previously described with very interesting results also in clinical trials [11,12]. The use of type 1 RIPs to construct ITs have several advantages: they are stable, safe to handle, numerous and often immunologically not correlated. Moreover, the wide variety of type 1 RIPs allows to select proteins with different characteristics, such as low systemic toxicity, high stability, etc.

This review summarizes the chemico-physical and structural properties of saporin-S6 and the characteristics of its endocytosis and intracellular routing. The pathogenetic mechanisms of the cell 
damage mediated by saporin-S6 are also described. Moreover, the recent progress and developments of saporin-S6-containing ITs in cancer immunotherapy are reported, considering both pre-clinical studies and clinical trials.

\section{Saporin-S6}

\subsection{Chemico-Physical and Structural Properties}

The first description of type 1 RIPs in soapwort seeds (Saponaria officinalis, Caryophyllaceae family) dates back three decades [13]. Since then, saporin-S6 has been the protagonist of more than a thousand studies reported in literature. Some important steps in the saporin-S6 timeline are reported in Figure 1.

Saporin-S6 belongs to a multigene family of proteins that includes more than nine different isoforms isolated from various plant tissues, such as leaf, root, and seed [14]. All isoforms differ from each other in both their chemico-physical and biological properties, but they all have a molecular weight of approximately $30 \mathrm{kDa}$. Saporin-S6 is the most representative of the seed isoforms, accounting for approximately $7 \%$ of the total seed protein content [13]. Saporin-S6 sequencing revealed heterogeneity at two positions, with either aspartic or glutamic acid in position 48, and either lysine or arginine present in position 91, which indicates that the saporin-S6 chromatographic peak contains a set of closely related saporin isoforms [15,16]. Notably, saporin-S6 is one of the most studied among the type 1 RIPs because of its strong activity both in cell-free systems and in cell lines.

Figure 1. Chronological advancements in the research on saporin-S6. Each reference is listed in the appropriate section of the main text.

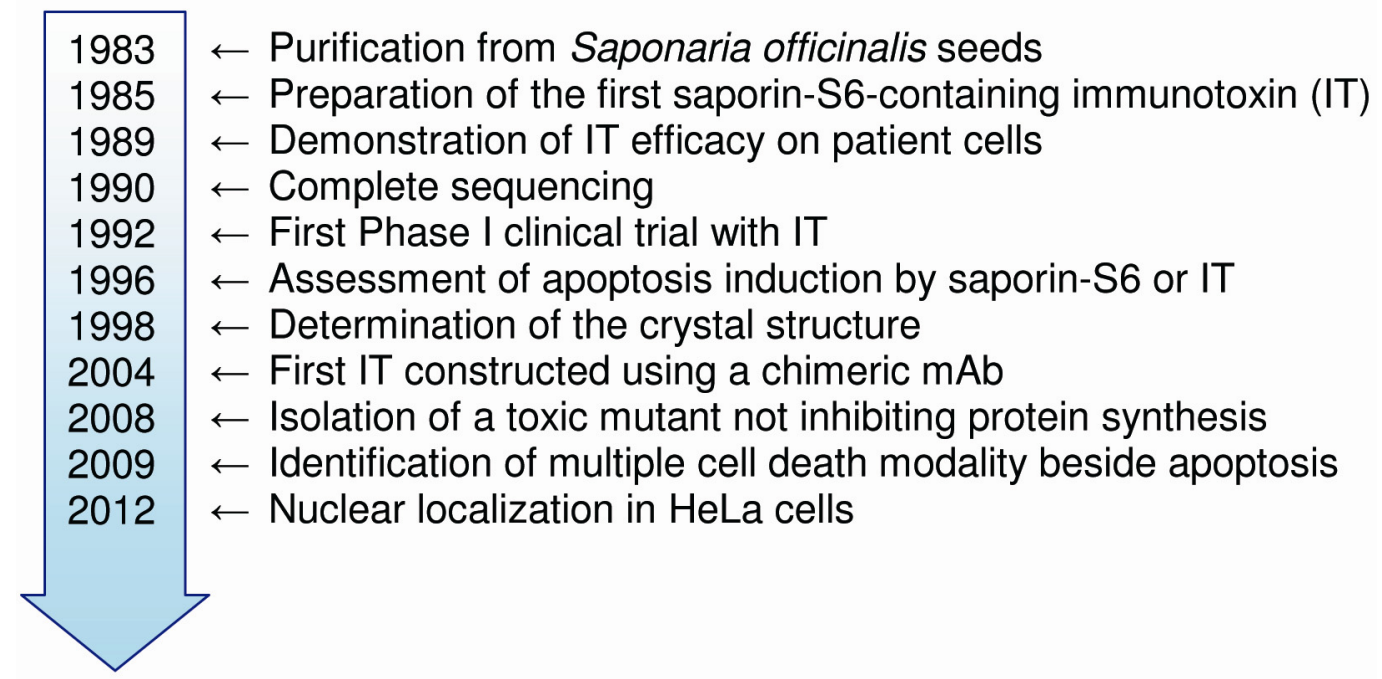

The mature form of saporin-S6 is 253 amino acids long. The sequence was determined in 1990 and almost $10 \%$ of the amino acids in saporin-S6 are lysine residues, a condition that confers to the protein an extremely high $\mathrm{p} I$ (approximately 10) [15]. No neutral sugars are present in the saporin-S6 molecule, despite the presence of glycosylation sites in the pro-saporin $C$-terminal extension sequence that is cleaved to form the mature protein. 
The $2.0 \AA$ resolution crystal structure of saporin-S6 showed that this protein contains two main domains: a predominantly $\beta$-stranded $N$-terminal domain and an $\alpha$-helix-rich $C$-terminal domain (Figure 2A). The $N$-terminal domain shows a high similarity to that of other RIPs. The $C$-terminal region includes a two stranded antiparallel $\beta$-sheet element connected by a short loop between the $\beta 7$ and $\beta 8$ strands; this structural motif is shorter than many other RIPs and may contribute to an increased accessibility to the substrate $[17,18]$.

Figure 2. Structural characteristics of saporin-S6. Ribbon model of the crystal structure (PDB 1QI7) (A) and catalytic site (B) of saporin-S6. The key residues of the enzymatic site are presented using a ball-and-stick model. Figures were produced by VMD 1.9.1 software. Electrostatic potential $(\mathbf{C})$ of the saporin-S6 surface at $\mathrm{pH}$ 7. The positive (blue) and the negative (red) regions are shown. The active pocket is highlighted by a yellow circle. The image was produced using the MOLMOL program.
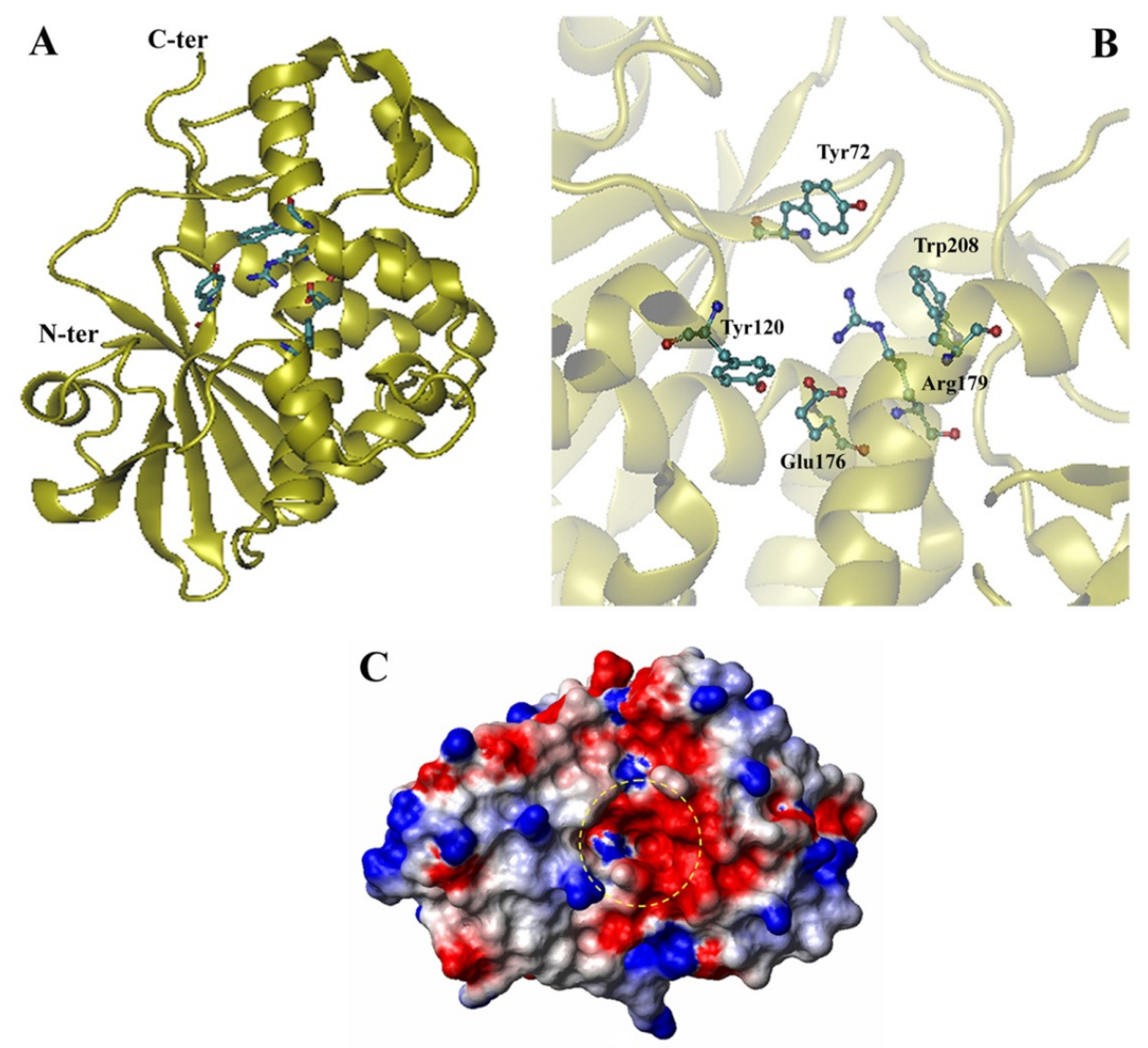

The active site is somewhat conserved among saporin isoforms. In saporin-S6, the residues

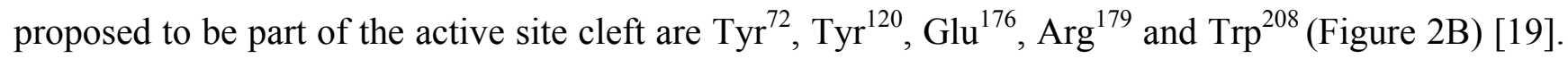
The residues Glu ${ }^{176}$, $\operatorname{Arg}^{179}$ and $\operatorname{Trp}^{208}$ cover the same position of other RIP three-dimensional structures, and $\mathrm{Tyr}^{72}$ assumes a different side chain conformation. This conformation is very important for RIP activity because this residue has been shown to be responsible for the interaction with the target adenine [18]. Because the active site residues are somewhat conserved amongst saporin isoforms and other RIPs [20], differences in the activity could be attributed to amino acid differences lying outside the active cleft. The mutation of residue $\operatorname{Asn}^{162}$ to $\mathrm{Asp}^{162}$ (N162D) is sufficient to significantly reduce saporin-S6 in vitro activity and cytotoxicity. In fact, Asn ${ }^{162}$ lies in close proximity to three 
hydrophobic residues, $\mathrm{Phe}^{149}, \mathrm{Ala}^{151}$ and $\mathrm{Val}^{153}$. The negative charge of the N162D substitution may affect the stability of the active cleft by introducing a local structural change [21].

The analysis of the surface electrostatic potential (Figure 2C) indicates a negative potential (colored in red) in the active site region. Two glutamate residues $\left(\mathrm{Glu}^{176}\right.$ and $\mathrm{Glu}^{205}$ ) are important for this negative charge. The small positive area (colored in blue) is due to the presence of only one arginine $\left(\mathrm{Arg}^{209}\right)$ at the entrance and two $\left(\mathrm{Arg}^{136}\right.$ and $\left.\mathrm{Arg}^{179}\right)$ inside the cavity of the active pocket [22].

Saporin-S6 is extremely resistant to high temperature, to denaturation by urea or guanidine and to attack by proteolytic enzymes [23]. Saporin-S6 is also very stable in response to chemical modifications such as those necessary for derivatization and conjugation procedures [24], and it is resistant to many freeze-thaw cycles (unpublished results from our laboratory). Altogether, these characteristics render saporin-S6 an interesting candidate for the construction of immunoconjugates.

\subsection{Endocytosis and Intracellular Localization}

Unlike type 2 RIPs, in which the presence of a lectin B-chain facilitates the endocytic mechanism, type 1 RIPs enter the cell with low efficiency. The cellular interaction of type 1 RIPs has been examined in many studies with inconclusive results. Particularly controversial is the debate regarding the mechanism of saporin-S6 endocytosis. It was initially suggested that saporin-S6, like all type 1 RIPs, enters cells through passive mechanisms such as fluid phase pinocytosis [25]. Saporin-S6 uptake by cells was described to occur by a mechanism that does not depend on specific binding sites [26]. However, the observations that some cell types show a moderate resistance to saporin-S6 cytotoxicity and that some organs are more sensitive to saporin-S6 intoxication led some researchers to search for a possible receptor. Receptor-mediated endocytosis through the $\alpha_{2}$-macroglobulin receptor, also called low-density lipoprotein receptor-related protein (LRP), was proposed as the binding mechanism for saporin-S6 [27]. A discrepancy was reported between the level of LRP and saporin-S6 cytotoxicity; i.e., LRP-positive or -negative cell lines showed similar sensitivities towards saporin-S6, suggesting a receptor-independent endocytosis mechanism [28].

Recently, electron microscopy experiments were performed, indicating that saporin-S6 endocytosis by HeLa cells mainly occurs through non-coated vesicles [29]. After initial internalization, saporin-S6 should reach its cytosolic targets to exert its cytotoxic activity. Most information on the intracellular trafficking of RIP was obtained via studies of the endocytic pathway of ricin. Once it enters the cell, ricin travels backward from the Golgi complex to the endoplasmic reticulum (ER), where the separated A-chain exploits the ER-associated degradation pathway to enter the cytosol [30]. A comparison between the endocytosis of ricin and saporin-S6 by Vero or HeLa cells was performed using immunofluorescence and treatment with brefeldin A or chloroquine, indicating that the type 1 RIP follows a Golgi-independent pathway to the cytosol and does not require a low $\mathrm{pH}$ for membrane translocation [31]. Chloroquine and monensin have been used to raise the $\mathrm{pH}$ of the endosomal compartment to evaluate the intracellular routing of saporin-S6 in a $\mathrm{CD} 30^{+}$cell line [32] and in a prostatic cancer cell line [33]. Because these substances had no effect on the cytotoxicity induced by saporin-S6, unlike that induced by ricin, the intracellular transport of saporin-S6 to the cytosol should not involve lysosomes or the Golgi cisternae. In addition, the translocation mechanism should be low-pH independent [32,33]. There is evidence of saporin-S6 localization within the ER, Golgi 
apparatus and nucleus in HeLa cells, indicating that saporin-S6 can reach various intracellular compartments, possibly by more than one pathway. Saporin-S6 was found localized intracellularly within 20 minutes of exposure. Double immunofluorescence analysis performed by confocal microscopy showed that approximately $30 \%$ of saporin-S6 colocalized with the ER marker BiP, and approximately 7\% co-localized with the Golgi apparatus, which was marked with GM130 [29]. Using transmission electron microscopy, after $20 \mathrm{~min}$ of incubation, gold-saporin-S6 molecules were seen mainly localized on the plasma membrane and in clear vesicles and vacuoles. Single gold particles were observed in sub-plasmalemmal clear vacuoles and free in the cytoplasm. After 40 min, saporin-S6 molecules were clustered in late endosomes and lysosomes in proximity to the nucleus and close to the rER cisternae. After 60 min of incubation, the nuclear localization of saporin-S6 was observed in approximately $10 \%$ of HeLa cells, with a gold labeling intensity ranging from moderate $(8 \%$ of cells containing $<10$ gold particles/nucleus $)$ to intense $(2 \%$ of HeLa cells showing $>10$ gold particles/nucleus) [29]. This study was the first report of saporin-S6 detection in cell nuclei. It must be underlined that these results were obtained with HeLa cells and they cannot automatically be extended to any other cell type. The nuclear localization of saporin-S6 has been postulated by another recent paper in U266 and IM-9 cells [34]. However, in this paper, the RIP was biotinylated and delivered as a complex with an antibody-avidin fusion protein, which could have altered the intracellular trafficking of the toxin as compared to that of saporin-S6 alone.

\subsection{Mechanisms of Intoxication and Cell Death Induced by Saporin-S6}

Various biological assays have been used to assess the ability of saporin-S6, both free and conjugated, to cause necrosis and apoptosis in pre-clinical models of human cancers. In particular, the replicative capability of tumor cells can be detected by thymidine incorporation or clonogenic assays; the cell viability can be evaluated by many tests, such as protein synthesis inhibition, tetrazolium salts reduction, ATP measurement, LDH release and many others. Apoptosis versus necrosis can be detected by annexinV/propidium iodide staining. Activation of caspases, TUNEL, a variation of mitochondrial membrane potential and nuclear morphology, are the most common methods to detect apoptosis. The evaluation of these parameters in pre-clinical studies is essential in the design of ITs in order to increase apoptotic cell death, thus reducing the side effects triggered by the inflammatory response to necrosis. Moreover, these analyses may be useful in clinical trials to understand the efficacy and stability of the chimeric drugs.

Experimental evidence has demonstrated the toxic effects of saporin-S6 both in vivo (in animal models) and in vitro (in many cell lines). In mice, an $\mathrm{LD}_{50}$ of $4.0 \mathrm{mg}$ of $\mathrm{RIP} / \mathrm{Kg}$ of body weight was calculated for saporin-S6. Intoxicated animals showed significant lesions in only three organs: the liver, spleen and kidney. After histopathological exam, the lesions revealed cell necrosis. Liver lesions were the most dramatic. Spleen lesions ranged from focal to more extensive necrosis of the red pulp. In kidney tissue, the proximal tubules were the most damaged [35]. No significant permanent lesions were observed after 14 days in mice intoxicated with saporin-S6 at non-lethal doses [36].

Most evidence about saporin-S6 cytotoxicity have been obtained by determining the inhibition of cellular protein synthesis or by determining the number of live (or dead) cells in comparison with untreated control cells by various viability/cytotoxicity tests. RIP activity is mostly expressed as the 
concentration that is able to inhibit $50 \%$ of protein synthesis $\left(\mathrm{IC}_{50}\right)$. The $\mathrm{IC}_{50}$ values for saporin-S6 reported in the literature can greatly vary (from 0.1 to $1000 \mathrm{nM}$ ), and the comparison between the numerous results available in literature is often difficult and arbitrary because of the heterogeneity of the experimental conditions, e.g., the type and/or number of cells used in the assays, the presence or absence of serum, the length of incubation with saporin-S6, the length of the experiment, etc.

Initially, the toxic effects of saporin-S6 were attributed to the inhibition of protein synthesis, but the observation that RIPs also depurinate DNA and other nucleic acids opened new perspectives about the mechanism of cytotoxicity. The first descriptions that saporin-S6 is able to kill cells via apoptosis were reported in 1996 [37,38] (Figure 1). Some apoptotic features, such as chromatin fragmentation, apoptotic bodies and hypodiploid cells, were found in lymphocytes and in many hematological cancer cell lines [37,38]. Caspase-dependent apoptosis in U937 cells was reported to be induced by saporin-S6 through a mitochondrial cascade, independently of translation inhibition. In this study, saporin-S6 was found to induce apoptosis via the intrinsic pathway and the activation of caspase 9; the absence of the activation of caspase 8 and truncated Bid could indicate that in this model the extrinsic pathway is not involved in mediating saporin-S6-induced apoptosis [39]. Instead, in L540 lymphoma cells, both caspase 8 and 9 are activated by saporin-S6. Caspase inhibitors of extrinsic (Z-IETD) and intrinsic (Z-LEHD) pathways as well as the pan-caspase inhibitor Z-VAD and the necroptosis inhibitor necrostatin-1 caused the partial rescue of L540 cells from death by saporin-S6. These results indicate that apoptosis is the main death pathway in cells intoxicated with saporin-S6, but it is not the only pathway [40]. Indeed, the cell killing mechanisms of RIPs are in part independent of caspase activation at least at the $\mathrm{IC}_{100}$ (concentration inhibiting $100 \%$ of protein synthesis), which was the concentration used in those experiments [40]. In the U87 glioblastoma cell line, the activation of ERK1/2 has been observed to forego caspase 8 or 9 activation after saporin-S6 treatment. This ERK1/2 activation might induce a cell cycle arrest in G1 phase with a decrease in D1 cyclin levels. Furthermore, the inhibition of protein synthesis could activate p53 [41].

The capability of saporin-S6 to induce apoptosis results not just from its ability to block protein synthesis, as different mutants lacking RIP activity can induce DNA fragmentation and apoptosis [42]. In 2008, it was reported that the onset of apoptosis is independent of protein synthesis inhibition [39].

To unify the intriguing results printed above, the following hypothesis may be put forward. Cell death by saporin-S6 may be induced by various cell injuries, including the inhibition of protein synthesis through RIP activity and DNA damage, either via $N$-glycosylase activity or as a result of oxidative stress-induction [34], or by other types of damage to the cell machinery that leads to apoptosis or different types of cell death (i.e., autophagy or necroptosis) (see Figure 3). In particular, the activation of the autophagic pathway may promote cell death as a result of cellular atrophy or leading to the execution of apoptotic or necrotic cell death programs [43].

The presence of saporin-S6 in the nucleus suggests that DNA damage could be one of the mechanisms used by this protein, and possibly other RIPs, to kill the cell, specifically by inducing DNA-dependent apoptotic death. In HeLa cells, a specific comet assay that detects DNA gaps resulting from the detachment of purinic/pyrimidinic bases was developed to investigate the possibility that saporin-S6 can reach the nucleus and exert its activity on DNA. The addition of endonuclease IV enabled the repair of nuclear damage in most cells, highlighting that the repair of DNA damage caused by base cleavage could be induced by the deadenylation activity of saporin-S6 [29]. 
Figure 3. Multiple cell death pathways induced by saporin-S6 containing immunotoxins (ITs). The scheme shows the broad range of cell death mechanisms triggered by ITs. Once Saporin-S6 reaches the cytosol or ER or nucleus it can cause apoptosis activation (both caspase-dependent or -independent apoptosis), autophagy, necroptosis, oxidative stress and the inhibition of protein synthesis (in red). Moreover, cell death can also be activated by the antibody (in green) occurring through apoptosis or, when full-length antibodies are used through complement-dependent cytotoxicity (CDC) and antibody-dependent cellular cytotoxicity (ADCC).

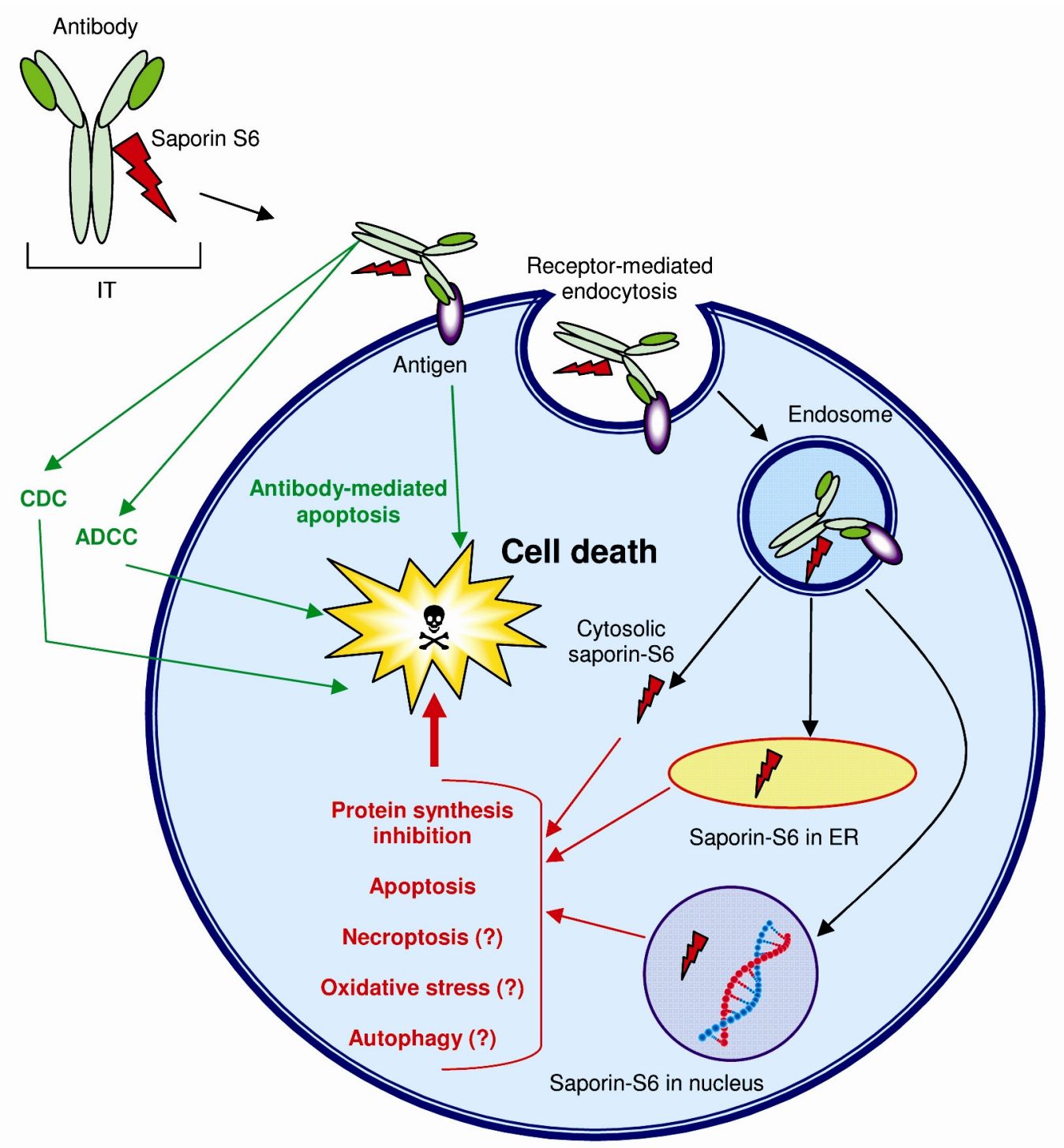

A global gene expression analysis of two human malignant B-cell lines revealed that an IT containing saporin-S6 could upregulate eleven genes involved in the cellular response to oxidative stress/DNA damage (KLF6, TXNIP, NFKBIE, CDC14B, BHLHB2, GADD45B, HIST2H4, TSC22D3, $R G S 1$ ) or involved in mRNA processing (THUMPD2, FYTTD1) [34]. The authors suggested that saporin-S6 induces in cells a transcriptional response dependent on oxidative stress/DNA damage, resulting in signal transduction blockage, cell cycle arrest and, consequently, apoptosis. 
In conclusion, it is likely that the cell damage induced by saporin-S6 represents a cell type-dependent multi-direction pathway in which apoptosis seems to be the main detectable effect in several different cell lines. For this reason, a better understanding of the molecular mechanism of saporin-S6 intoxication could be helpful to designing an optimal therapeutic application. In fact, the possibility of modulating neoplastic cell killing through different ways adds new opportunities to develop combined synergistic immuno- and chemo-therapy, overcoming the problem of drug resistance.

\section{Immunotoxins}

When toxins are conjugated to targeting proteins, they can be specifically delivered toward unwanted cells responsible for diseases. Antibodies and their fragments have been the most utilized carriers, but other molecules have also been employed, such as hormones, growth factors, antigens, cytokines and others [44]. The term "immunotoxin" generally refers to a toxin targeted by an antibody, either intact or a fragment, whereas toxins linked to other carriers are more commonly referred to as "chimeric toxins" or simply "conjugates".

To date, ITs have provided excellent results in hundreds of different models in pre-clinical studies $[6,11,45]$ and in clinical trials $[12,46]$. The best results have been obtained in cancer therapy, especially in hematological malignancies. The efficiency of an IT in killing the target cells mainly depends on the cell type, antigen density, binding affinity and intracellular routing.

The main reported undesirable consequences of ITs in clinical therapy are immunogenicity, and vascular leak syndrome (VLS). Anti-toxin antibodies are produced by approximately $90 \%$ of epithelial cell cancer patients after 1 or 2 cycles of treatment with ITs [9]. However, patients with hematologic cancers show a lower incidence of anti-toxin antibodies, which is detectable only after several cycles of therapy [9]. This occurs because end-stage onco-hematological patients are often heavily immunosuppressed. VLS is caused by an increase in vascular permeability due to endothelial cell damage. VLS is associated with an extravasation of fluids into tissues with consequent edema, hypotension and, in severe form, signs of pulmonary and cardiovascular failure [47].

Despite the presence in literature of a large number of studies with ITs containing different toxic moieties (plant and bacterial toxins, enzymes, drugs, etc.), the published results are often not comparable each other because of the difference in the carrier moiety, the target cells and the experimental conditions, also when ITs are directed to the same target molecule. When ITs containing different type 1 RIPs or the ricin A chain linked to the same antibody were compared in the same in vitro experiment, those containing saporin-S6 always resulted the most, or one of the most effective [11].

The use of saporin-S6-containing ITs to treat hematological tumors often revealed a certain grade of toxicity for bone marrow, due to the expression of the targeted antigen on various normal, hematopoietic progenitor cells. However, in different studies it has been demonstrated that although the ITs may be cytotoxic against committed progenitor cells, these cells can be repopulated by the pluripotent progenitors that are not affected by treatment with the conjugates $[34,48,49]$.

Additionally, saporin-S6 has been utilized in neuroscience studies in which it has been conjugated to specific molecules (e.g., substance P, anti-NGFR antibodies) for the purpose of selectively destroying neurons. The permanent and selective killing of neurons is an important model for the study of behavior, neuronal loss (e.g., Alzheimer's disease), etc. Several studies were performed in animals 
with saporin-S6-containing ITs that aimed to suppress some forms of strong chronic pain through the permanent removal of a small number of spinal neurons, which transmit chronic pain signals, without affecting the sensitivity to acute pain. Despite the importance of these studies, they are not a topic of the present review, and thus we refer the reader to specific reviews on the subject (e.g., [50,51]).

\subsection{Chemical and Recombinant Immunotoxins}

First-generation RIP-based ITs were produced by chemically coupling native toxins to antibodies by the formation of disulfide bonds that connect the toxic moiety to the carrier. Chemically coupled ITs have several advantages: they are relatively simple to produce at high yields, and they have good stability. The main disadvantage is represented by their heterogeneous composition.

A new generation of ITs was produced using recombinant DNA techniques, and they are called recombinant ITs. They are obtained by linking the gene portion encoding the antigen-binding fragments of an antibody ( $\mathrm{Fab}$ or $\mathrm{Fv}$ ) to the gene encoding the native catalytic domain or a mutated version of the toxin. The resulting construct can be expressed in various hosts, such as bacteria [52], yeast [53] or algae [54]. The first generated recombinant ITs utilized single-chain variable fragments (scFvs) as carrier moiety, but they were then substituted by disulfide-stabilized Fvs (dsFvs). In the $\mathrm{scFv}$ fragment, the antigen-binding portion of the heavy-chain variable region is connected by a short linker to the variable region of the light chain [55], but in dsFvs the peptide linker was replaced by a disulfide bond, which confers them enhanced stability [44]. Moreover, a panel of new partially or fully humanized antibodies was employed as a carrier moiety to minimize the risk of immunogenicity and toxicity in patients.

\subsection{Immunotoxins Containing Saporin-S6}

The remarkable resistance to denaturation, proteolysis and chemical modifications as well as its high enzymatic activity and low cytotoxicity as an unconjugated molecule (as detailed in Section 2) suggests that saporin-S6 represents an ideal candidate for the construction of conjugates for therapeutic use. In 1985, saporin-S6 was conjugated for the first time to the murine anti-Thy $1.1 \mathrm{mAb}(\mathrm{OX} 7)$ and to its $\mathrm{F}\left(\mathrm{ab}{ }^{\prime}\right)_{2}$ fragment [56]. In 1989, the cytotoxicity of the OKT1(murine)/saporin-S6, an anti-CD5 IT, was evaluated on fresh chronic B lymphocytic leukemia cells from 31 patients [57]. Since then, saporin-S6 has been largely used as a toxic moiety in a variety of immunoconjugates targeting different malignant hematological cells and solid tumors, with promising results in several pre-clinical studies. Hematological cells represent the best candidate for targeted therapy because they offer surface target antigens that are easier to access in vivo than do solid tumor cells.

In this section, we describe the experiments that have been carried out with saporin-S6-containing ITs. The paragraphs are organized based on the origin of the utilized antibody, that is, murine, chimeric, humanized or scFv. For each category, the results are grouped according to the recognized molecular target, treating both hematological and solid tumors. For a more complete review of saporin-S6-containing ITs, we direct the reader to the review by Polito et al., 2011 [12]. 


\subsubsection{ITs Containing Saporin-S6 and Murine mAbs (and Other First Generation Abs)}

Saporin-S6 was first conjugated to murine anti-CD2 mAbs (GT2, OKT11, 8E5B3, 8G5B12 and 7A10C9) to produce several ITs that showed an increased cytotoxicity compared to native saporin-S6. Anti-CD2 conjugates evaluated in vitro were found to inhibit protein synthesis with $\mathrm{IC}_{50} \mathrm{~s}$ ranging from 0.1 to $100 \mathrm{pM}$ [58]. Similar in vitro efficacy was observed for an anti-CD7 HB2/saporin-S6 IT, which had an $\mathrm{IC}_{50}$ in the $\mathrm{pM}$ range. When tested in a mouse model of human T-cell leukemia, this IT showed a therapeutic effect with a single intravenous (i.v.) dose of $10 \mu \mathrm{g}$ of IT $(0.5 \mathrm{mg} / \mathrm{kg})$, achieving $50 \%$ survival at day +150 [59]. Further studies on this IT provided additional interesting information about the in vivo therapeutic efficacy of HB2/saporin-S6. In fact, the conjugation of saporin-S6 to an HB2 $\mathrm{F}(\mathrm{ab})_{2}$ fragment, which is incapable of recruiting NK cells, led to the lowered in vivo efficacy of the IT [60]. A decreased activity of HB2/saporin-S6 was also shown in the treatment of a NOD/SCID mouse leukemia model, which has reduced cytolytic NK activity [61]. Taken together, these findings suggest that host-mediated antibody-dependent cell cytotoxicity (ADCC) positively contributes to HB2/saporin-S6 efficacy. Further attempts to improve the in vivo efficacy of this IT, both with the insertion of hindered or non-hindered disulfide cross-linkers or the coupling of one or two saporin-S6 moieties per IT molecule, failed to achieve significant differences in terms of pharmacokinetic and therapeutic effects $[62,63]$. The BU12 anti-CD19 mAb covalently coupled to saporin-S6 showed an $\mathrm{IC}_{50}$ in the $\mathrm{nM}$ range for the $\mathrm{CD} 19^{+} \mathrm{B}$-cell acute lymphoblastic leukemia cell line NALM- 6 . In SCID mice injected with NALM-6, BU12 IT administration $(3 \times 10 \mu \mathrm{g}$ total, each injection being given i.v. on alternate days, i.e., 7, 9 and 11 days after tumor cell injection) led to a significantly prolonged survival versus sham-treated controls, with $40 \%$ of animals alive and disease free at +110 days [64]. A very strong in vitro efficacy was observed with saporin-S6 conjugated to the anti-CD22 mAb OM124, with $\mathrm{IC}_{50} \mathrm{~s}$ ranging from 0.001 to $10 \mathrm{pM}$. The in vivo treatment of SCID mice bearing transplanted Daudi cells with $0.5 \mathrm{mg} / \mathrm{kg}$ of OM124/saporin-S6 given at days $+1,+4,+7$ after tumor injection resulted in $33 \%$ of the animals being tumor-free at day +220 . The combination therapy with cyclophosphamide $(60 \mathrm{mg} / \mathrm{kg}$ ) given on days +1 and +2 , and the administration of this IT on days +1 , $+4,+7$ showed a better efficacy with $66 \%$ of the animals being tumor-free at day +220 [65].

The efficacy of an anti-CD38 IB4/saporin-S6 was evaluated in different CD38 ${ }^{+}$human cell lines and in $\mathrm{CD}_{3} 8^{+}$malignant cells from a non-Hodgkin lymphoma (NHL) patient. All of the cell lines tested were found to be very sensitive to this $\mathrm{IT}$, with $\mathrm{IC}_{50} \mathrm{~S}$ in the $\mathrm{pM}$ range. The neoplastic $\mathrm{CD} 38^{+}$ cells obtained from the NHL patient were completely eliminated with IB4/saporin-S6 at $10 \mathrm{nM}$ concentration [66]. $\mathrm{IC}_{50}$ s lower than $10 \mathrm{nM}$ were observed in vitro for the anti-CD80 B7-24/saporin-S6 in $\mathrm{CD}^{+} 0^{+} \mathrm{B}-$ cell line, Raji, and in Reed-Sternberg cell lines HDLM2 and KM/H2 [67]. The anti-CD80 mAb M24 conjugated to saporin-S6 exhibited strong cytotoxicity against Raji and L428 cell lines, with $\mathrm{IC}_{50} \mathrm{~S}$ in the $\mathrm{pM}$ range. In the same experiments, an anti-CD86 1G10/saporin-S6 IT was almost $1 \mathrm{log}$ less toxic than M24/saporin-S6 [49]. Two plasma cell-reactive mAbs, B-B2 and B-B4, were conjugated to saporin-S6 for the immunotherapy of multiple myeloma. Both of these ITs were found to be suitable for ex vivo bone marrow purging and showed no reactivity with hemopoietic precursor cells. B-B4 was the more effective of the two conjugates [68].

The mAb Ber-H2 was conjugated with saporin-S6 giving an IT that specifically inhibits protein synthesis in Hodgkin-derived cell lines with $\mathrm{IC}_{50}$ s ranging from 0.01 to $1 \mathrm{pM}$ [69]. In a SCID mouse 
model of human xenografted $\mathrm{CD}^{+} 0^{+}$anaplastic large-cell lymphoma (ALCL) (JB6 cell line), a 3-day treatment with non-toxic doses of Ber-H2/saporin-S6 $\left(50 \%\right.$ of $\left.\mathrm{LD}_{50}\right)$ induced complete remission in $80 \%$ of mice when treatment started $24 \mathrm{~h}$ after tumor transplantation, and $30 \%$ of complete remission when started at a later stage (40-60- $\mathrm{mm}^{3}$ tumor volume) [70]. Strong anti-tumor activity of the same IT was also observed in another SCID mouse model of ALCL (D430B cell line). A dose of $0.1 \mathrm{mg} / \mathrm{kg}$ IT given $48 \mathrm{~h}$ after tumor transplantation caused complete remission in 4/6 mice and partial remission in $2 / 6$ mice [71].

The polyclonal antibody ATG Fresenius-S was prepared by immunizing rabbits with non-fractionated human thymocytes isolated by Ficoll density gradient centrifugation. ATG was conjugated to saporin-S6, and the resulting IT showed a strong cytotoxic effect on lymphoma- and leukemia-derived cell lines. This IT enhanced saporin-S6 toxicity by approximately $2-3 \operatorname{logs}$ and induced a time-dependent activation of caspase-3/7 in Raji cells [72].

Unlike malignant hematological cells, ITs reach solid tumor cells poorly, mainly due to non homogeneous cancer vasculature and high interstitial pressure that obstacle IT diffusion into the cancer mass. Moreover, other obstacles are represented by the less availability of cancer specific antigens and often the worse cellular internalization of the immunocomplex in solid tumors respect than hematological ones. For these reasons, ITs often showed good in vitro anti-tumor efficacy on solid tumors, but in animal models they gave less resounding results than those described on hematological tumors [11,12]. Several ITs have been obtained by conjugating saporin-S6 to murine mAbs that recognize antigens on solid tumor cells. Ep2/saporin-S6 IT, which recognizes the high molecular weight melanoma-associated antigen showed an in vitro $\mathrm{IC}_{50}$ of approximately $0.1 \mathrm{nM}$, while it did not affect antigen-negative melanoma cells at $100 \mathrm{nM}$ dose [73]. Loco-regional administrations (e.g. intravesical, intrathecal, etc. applications) could be useful to by-pass most IT disadvantages. The 48-127/saporin-S6 IT recognizing gp54, a glycoprotein that is expressed on all human bladder tumors, showed an in vitro $\mathrm{IC}_{50}$ in the $\mathrm{nM}$ range on the target $\mathrm{T} 24$ cell line. The authors demonstrated that a $2 \mathrm{~h}$ incubation of the cells with the IT was sufficient to ensure optimal binding and endocytosis, thus the IT maintained the complete anti-tumor efficacy in a time compatible with bladder irrigation [74]. Tumor cells generally express higher level of transferrin receptor (TfR) than normal tissues, this led many researchers to utilize TfR as target for immunotherapy. The efficacy of an anti-TfR murine mAb conjugated to saporin-S6 was compared to transferrin/saporin-S6 conjugates. Both conjugates were found to be equally effective with $\mathrm{IC}_{50}$ in $0.1 \mathrm{nM}$ range, but the transferrin/saporin-S6 conjugate, although presenting a minor risk with regard to immunogenicity, was influenced in vivo in its efficacy by free transferrin and iron saturation, whereas the anti-TfR/saporin-S6 IT was not as subdued by these influences [75]. The in vivo efficacy of an anti-receptor protein tyrosine phosphatase $\beta \mathrm{mAb}$ conjugated to saporin-S6 was evaluated in athymic nude mice bearing the U87 glioblastoma cells. The IT was given intrathecally once tumors had reached a mean tumor volume of $130 \mathrm{~mm}^{3}$ at doses of 15 and $30 \mu \mathrm{g}$ twice a week for two weeks, the IT was able to slow down tumor growth by $25 \%$ and $73 \%$, respectively. The medium survival time of mice was prolonged from 18.6 days (PBS) to 32.1 (IT $30 \mu \mathrm{g}$ ). The IT did not cross-react with the investigated tissues (colon, kidney, liver, small intestine, and stomach) [76]. 


\subsubsection{Immunotoxins Containing Saporin-S6 and Chimeric mAbs}

Chimeric antibodies have been developed in order to eliminate the human anti-mouse antibody response seen in patients treated with murine antibodies. The chimerization process involves the replacement of mouse constant domains with human constant domains, thereby eliminating the immunogenic portions without altering the specificity for the target.

Rituximab is an anti-CD20 chimeric mAb that is widely used as single agent for the treatment of patients with CD $20^{+} \mathrm{NHL}$ or chronic lymphocytic leukemia. In 1997, Rituximab was approved by the US FDA for the treatment of recurrent/refractory follicular NHL and of untreated aggressive NHL in combination with the cyclophosphamide-hydroxydaunorubicin-oncovin-prednisone (CHOP) regimen [77]. Rituximab/saporin-S6 was the first IT in which saporin-S6 was conjugated to a chimeric mAb. This IT exhibited strong cytotoxicity in target cells and inhibited $50 \%$ of protein synthesis at a concentration of approximately $0.2 \mathrm{nM}$. The conjugate also induced apoptosis in $95 \%$ of treated cells at a concentration of $10 \mathrm{nM}$. The cytotoxicity of Rituximab/saporin-S6 was augmented by the co-administration with the chemotherapy drug fludarabine, leading to the complete elimination of the malignant population [78].

The anti-hTfR IgG3-Av, consisting of a mouse/human chimeric IgG3 genetically fused to chicken avidin, was conjugated to biotinylated saporin-S6. This IT resulted strongly cytotoxic in myeloma cells expressing different levels of TfR, activating multiple cell death pathways simultaneously [79].

The ch25A11/saporin-S6 IT specifically recognizes the CUB domain-containing protein 1 that is expressed by prostate cancer cells. This IT was evaluated in vivo in SCID mice bearing prostate carcinoma cells and demonstrated a fairly good anti-tumor activity. The dose-finding study showed that the optimal regimen for mice bearing PC-3 cells $\left(3 \times 10^{6}\right)$ injected with ch25A11/saporin-S6 at $0.4 \mathrm{mg} / \mathrm{kg}$ was a three-dose treatment on days $+7,+10$, and +17 . The IT caused acute toxicity, shown by the acute, but reversible body weight loss 1 day after injection, but all the mice recovered their weight after the treatment. Tumor growth was inhibited by approximately $65 \%$ by IT only when administered i.v., whereas the IT inhibited tumor metastasis when it was administered both i.v. and subcutaneously [80].

\subsubsection{Immunotoxins Containing Saporin-S6 and Humanized mAbs}

Further improvements of chimeric mAb immunogenicity and efficacy have led to the construction of humanized mAbs in which only the hypervariable regions are of murine origin.

Epratuzumab is a humanized $\mathrm{mAb}$ that selectively binds the CD22 antigen. The Epratuzumab/saporin-S6 IT showed strong in vitro cytotoxic effects demonstrated by the complete loss of viability, the total inhibition of protein synthesis and the induction of apoptosis in $\mathrm{CD} 22^{+}$target cell lines at concentrations of approximately $0.1-1 \mathrm{nM}$. This IT showed potent anti tumor activity in a SCID mouse Raji xenograft model of aggressive human lymphoma [81,82]. The anti-CD22 IT HB22.7/saporin-S6 exhibited strong cytotoxicity in NHL cell lines showing $\mathrm{IC}_{50}$ values in $10 \mathrm{pM}$ range and completely prevented tumor development in athymic nude mice when the treatment was started within 24 hours from tumor inoculation, whereas the mixture of free HB22.7 and saporin-S6 did not exert cytotoxicity [83]. Moreover, in NOD/SCID xenograft mice, the IT increased the median survival time from 20 (control mice) to over 50 days (treated mice) [84]. 
With regard to solid tumors, the humanized biotinylated mAb hJ591 (anti-PMSA) was conjugated to streptavidin-saporin-S6, and its cytotoxic effects were evaluated in prostate cancer cells and in an LNCaP xenograft model in athymic nude mice. In cell lines, the IT showed $\mathrm{IC}_{50}$ values in the $\mathrm{nM}$ range and induced apoptosis in $40 \%-60 \%$ of target cells. The IT caused a reduction in tumor growth in treated mice by approximately 5- to 6-fold with respect to the control mice [85].

\subsubsection{Immunotoxins Containing Saporin-S6 and Single-Chain Variable Fragments}

Variable fragments are the smallest functional units of antibody molecules required to maintain the structure and specificity of the whole antibody. Because of their small sizes, scFv containing ITs can access solid tumors more easily than ITs containing whole mAbs. However, the scFvs have also some disadvantages as the loss of CDC and ADCC activities, due to the lack of the Fc portions. Moreover they have shorter half lives in blood than the whole antibodies.

Treatment with the anti-CTLA-4 scFv-83/saporin-S6, scFv-67/saporin-S6 and scFv-40/saporin-S6 ITs resulted in specific cytotoxicity against activated T lymphocytes and for several target cell lines [86]. The scFv-83/saporin-S6 IT was able to induce apoptosis at a concentration of $10 \mathrm{nM}$ in more than $90 \%$ of treated acute myeloid leukemia patient cells [87]. This IT was also tested in a model of tumor rejection consisting of $\mathrm{C} 57 \mathrm{BL} / 6$ mice bearing a murine H.end endothelioma cell line derived from $\mathrm{DBA} / 2$ mice. Lymphoid infiltration was notably reduced, demonstrating that this IT was active in vivo. The toxicity of the IT I/F8 scFv/saporin-S6 was assayed on both human and murine ALCAM/CD166 ${ }^{+}$ cell lines, and toxicity was at least 100 -fold higher than that of free saporin-S6 with $\mathrm{IC}_{50} \mathrm{~S}$ in the nM range [88].

\subsubsection{Saporin-S6-Containing Immunotoxins in Clinical Trials}

The few saporin-S6-containing ITs that have entered clinical trials so far have generated very interesting results. Below, we summarize the main results obtained in the treatment of hematological malignancies.

The first phase I/II clinical trial with a saporin-S6-containing IT was carried out in 1992 using the anti-CD30 Ber-H2/saporin-S6 IT $(0.2 \mathrm{mg} / \mathrm{kg}$, as RIP, in one or two weekly doses i.v. $)$ in four patients with advanced refractory Hodgkin's disease (HD), achieving promising results with only mild and transient side effects. A reduction in tumor mass was observed in all patients, with $75 \%$ of them achieving partial remission and 50\% displaying a complete relief of systemic symptoms with responses lasting 6-10 weeks [89]. The enrollment of twelve patients with advanced HD extended the same trial. The final results of this study included a tumor mass reduction in $60 \%$ of cases, with partial remission in approximately $42 \%$ of patients and a minor response in $17 \%$. Responses lasted between 2 and 4 months [90].

Side effects observed in about $70 \%$ of patients included fever, myalgias, grade I VLS, thrombocytopenia and a transient increase in transaminases. The maximum tolerated dose, as defined by a grade III reversible VLS, was reached in one patient at dosage of $0.2 \mathrm{mg} / \mathrm{kg}$ as saporin-S6 $(0.8 \mathrm{mg} / \mathrm{kg}$ as IT), given as single administration. Some of the IT related symptoms, such as fever and myalgias, were abolished by concomitant steroid therapy. In all patients, Abs against both the murine $\mathrm{mAb}$ and the toxin were detected 2-4 weeks after the treatment $[89,90]$. 
Bispecific $\mathrm{F}\left(\mathrm{ab}^{\prime}\right)_{2}$ antibodies (4KB128 and HD6) were employed to target saporin-S6 to the CD22 surface antigen in the treatment of lymphoma in two Phase I/II clinical trials. One patient with end-stage NHL received a total of $5 \mathrm{mg}$ of saporin-S6 complexed with a pair (50 mg) of anti-CD22 bispecific Abs over 15 days $(0,+7,+15)$, achieving a complete clearance of the tumor from the blood, clearance of the ascites and shrinkage of the tumor masses. The patient showed no sign of an anti-saporin-S6 response, but developed a strong anti-mouse Fab response 28 days after the treatment began. In the same trial another patient with end-stage chronic lymphocytic leukemia, treated with the bispecific $\mathrm{F}(\mathrm{ab})_{2}$ antibody RFB-9 targeting saporin-S6 to the CD19 antigen (total of $10 \mathrm{mg}$ of saporin-S6 complexed to $100 \mathrm{mg}$ of anti-CD19 bispecific $\mathrm{Ab}$, at days $0,+7,+28,+42$ ), showed no therapeutic effect over 45 days. Neither patient experienced any toxic side-effects [91]. Five low-grade, end-stage, B-cell lymphoma patients received between 3 and 6 doses of the above described anti-CD22 ITs with weekly infusions containing escalating doses of the complexes (ranging from 1 to $4 \mathrm{mg}$ /dose, for a total of 5-20 $\mathrm{mg}$, as RIP).

Only grade I toxic effects were seen, with mild fever, weakness and myalgia for 1-2 days after the treatment. All weekly treatments were well tolerated; the only significant toxicity was slight inflammation of the vein used for infusion (2/5), some myalgias and general weakness for 24 to $48 \mathrm{~h}$ after the treatment. There was no evidence of weight gain or other signs of VLS. Only one patient developed an antibody response to the infused complexes, both against antibody and saporin-S6. All patients showed rapid and significant responses to the treatment, and all showed at least a $50 \%$ reduction in measurable disease even if no response persisted for the 28 days necessary for the definition of a partial response [92,93].

\subsubsection{New Strategies to Improve Saporin-S6 Immunotoxins in Cancer Therapy}

Some efforts have been made to enhance the toxicity of saporin-S6 alone or as ITs in order to develop a new therapeutic approach for the treatment of neoplasms, especially solid tumors. A further improvement of saporin-S6-based therapy could lead to the better design of ITs and related delivery strategies to improve saporin-S6-based anti-tumor therapy.

One of the strategies employed to enhance IT cytotoxicity is the photochemical internalization (PCI) of therapeutic molecules. PCI is a drug delivery method for the cytosolic release of drugs from the endocytic compartment. The method takes advantage of the use of photosensitizers that localize to the membrane of the endocytic vesicles and their ability to cause membrane breakage and the subsequent release of entrapped drug into the cytosol after controlled light exposure. As ITs are taken up by receptor-mediated endocytosis [1], the combination of targeted therapy with the PCI technology, during which light-activation of the drug is constrained to the tumor, should be particularly beneficial. In fact, this strategy provides a wider therapeutic window for the targeting drug and should improve efficacy, especially in the treatment of solid tumors. It has been shown that PCI synergistically enhances the cytotoxicity of cetuximab/saporin-S6, an IT targeting EGFR, which consists of the chimeric $\mathrm{mAb}$ cetuximab bound to saporin-S6 by a biotin-streptavidin linkage. The PCI treatment enhanced the cytotoxicity of the IT in a synergistic manner in EGFR-expressing carcinoma cell lines derived from different tumor tissues [94]. PCI was also found to enhance the toxicity of anti-HER2 trastuzumab/saporin-S6 IT on trastuzumab-resistant HER2+ Zr-75-1 cells, even though a higher 
concentration of this IT was required to achieve a similar cytotoxic effect with respect to cetuximab/saporin IT (100 pM versus 3 pM, respectively) [95]. In addition, PCI was found to be an efficient method for the selective killing of $\mathrm{CD} 133^{+}$cancer cells that have cancer stem cell properties and are resistant to photodynamic therapy. PCI of the anti-CD133 saporin-S6-containing ITs efficiently depleted sarcoma cells at $\mathrm{fM}$ concentrations, leading to a reduced sarcoma tumor-initiating capacity. Sarcoma cells with stem cell properties were also subjected to sub-toxic treatments to allow the transplantation of viable cells in NOD/SCID IL2R $\gamma$ mice, confirming the reduced tumor-initiating capacity after IT treatment [96,97].

Another improvement of saporin-S6-based ITs results from their combination with a mixture of saponins, which are in general tenside-like compounds able to interact with cholesterol within membranes. This combination was found to enhance saporin-S6 toxicity [98], so the employment of saponins has been used to ameliorate the intracellular uptake of saporin-S6-based ITs in solid tumors. The combined application of saponins with the hEGF/saporin-S6 IT showed a 6900-fold enhancement in the in vitro cytotoxic efficacy against target cells. In vivo studies in over-expressing, EGFR-tumor bearing mice showed a reduction in the average tumor size of more than $90 \%$ as a result of this combined therapy $[99,100]$.

Another approach to selectively target saporin-S6 to malignant cells is to encapsulate the toxin into targeted nanoparticles, such as liposomes, nanoemulsions, solid lipid nanoparticles, polymeric nanoparticles, dendrimers, carbon nanotubes and magnetic nanoparticles. The size of particles used for medical purposes is preferably in the 5-200 nm range. Their conjugation to mAbs allows the site-directed delivery of drugs toward specific targets. Saporin-S6 was loaded into targeted cationic liposomes and PEG-liposomes, and their cytotoxicity was evaluated in vitro. These conjugates showed enhanced toxicity with respect to saporin-S6, especially in combination with the PCI technique [101].

\section{Conclusions}

The chemico-physical and structural properties of the type 1 RIP saporin-S6 allow for understanding some reasons for its success as a toxic moiety of ITs. First, the accessibility of the active site to the substrate could justify the high enzymatic activity; second, the high resistance to proteolysis surely contributes to the stability of the enzyme. Indeed, saporin-S6 shows good resistance to blood and endosomal proteases. Moreover, it well maintains its properties after chemical modifications and conjugation processes. In addition, studies on cell interaction and intracellular routing have shown the low level of unspecific toxicity, due to the scarce ability of the saporin-S6 to enter the cell in absence of a specific carrier. On the other hand, once the endocytosis is facilitated, this RIP may reach many cellular compartments, where it appears to have a wide range of possible intracellular substrates, thus triggering multiple cell death pathways, rendering impossible the selection of RIP-resistant mutants (Figure 3).

Because of all the characteristics reported above, saporin-S6 could represent the ideal toxic moiety to obtain conjugates, as also demonstrated by the numerous publications reporting interesting results (Table 1). In fact, saporin-S6 has been utilized to construct conjugates and ITs against several targets in many pre-clinical studies, leading to promising outcomes in most cases. The great efficacy has been reported in different models of hematological tumors. In the experiments conducted on mice, 
treatment with saporin-S6-containing ITs was able to strongly reduce the size of transplanted tumors in all cases, and in several models, completely eliminate tumor masses. Moreover, saporin-S6 ITs have a multifaceted cytotoxicity due to the combined death mechanisms of both the antibody and RIP.

Table 1. Summary of the main saporin-S6 containing ITs.

\begin{tabular}{|c|c|c|c|c|}
\hline \multicolumn{5}{|c|}{ Hematological Tumors } \\
\hline Antibody & Origin & Antigen Target & Tumor & Reference \\
\hline $\begin{array}{l}\text { GT2, OKT11, 8E5B3, } \\
\text { 8G5B12, 7A10C9 }\end{array}$ & Murine & $\mathrm{CD} 2$ & T-cell chronic lymphocytic lymphoma & {$[58]$} \\
\hline OKT1 & & CD5 & B lymphocytic leukemia & {$[57]$} \\
\hline HB2 & & CD7 & T-cell acute lymphoblastic leukemia & {$[59]$} \\
\hline BU12 & & CD19 & B-cell lymphoblastic leukemia & {$[64]$} \\
\hline OM124 & & $\mathrm{CD} 22$ & B lymphoblastoid, Burkitt's lymphoma & {$[65]$} \\
\hline $\mathrm{F}\left(\mathrm{ab}^{\prime}\right)_{2} \mathrm{BsAb}$ & & & Non-Hodgkin's lymphoma & {$[91,93]$} \\
\hline $4 \mathrm{~KB} 128+\mathrm{HD} 6$ & & & B-cell lymphoma & {$[92]$} \\
\hline BerH2 & & $\mathrm{CD} 30$ & $\begin{array}{c}\text { Hodgkin's disease, } \\
\text { Anaplastic large-cell lymphoma }\end{array}$ & $\begin{array}{c}{[69-71} \\
89,90]\end{array}$ \\
\hline IB4 & & CD38 & Non-Hodgkin's lymphoma & {$[66]$} \\
\hline B7-24 & & CD80 & Burkitt's lymphoma, Hodgkin's disease & {$[67]$} \\
\hline $\mathrm{M} 24+\mathrm{IG} 10$ & & CD80/CD86 & Burkitt's lymphoma, Hodgkin's disease & {$[49]$} \\
\hline B-B2, B-B4 & & CD138 & Multiple myeloma & {$[68]$} \\
\hline ATG & Rabbit & Various & Lymphoma and leukemia cells & {$[72]$} \\
\hline Rituximab & Chimeric & $\mathrm{CD} 20$ & Non-Hodgkin's lymphoma & {$[78]$} \\
\hline Anti-hTfR IgG3-Av & & TfR & Myeloma & {$[34,79]$} \\
\hline Epratuzumab & Humanized & $\mathrm{CD} 22$ & Non-Hodgkin's lymphoma & {$[81,82]$} \\
\hline HB22.7 & & & $\begin{array}{l}\text { Non-Hodgkin's lymphoma, } \\
\text { Acute lymphoblastic leukemia }\end{array}$ & {$[83,84]$} \\
\hline $\begin{array}{c}\text { scFv-83, scFv-67, } \\
\text { scFv-40 }\end{array}$ & $\mathrm{scFv}$ & CTLA4 & $\begin{array}{c}\text { Activated T lymphocytes, } \\
\text { Myeloid leukemia }\end{array}$ & {$[86,87]$} \\
\hline \multicolumn{5}{|c|}{ Solid Tumors } \\
\hline Antibody & Origin & Antigen Target & Tumor & Reference \\
\hline Ep2 & Murine & HMW-MAA & Melanoma & {$[73]$} \\
\hline $48-127$ & & gp54 & Bladder tumor & {$[74]$} \\
\hline $42 \cdot 6.3$ & & TfR & Glioblastoma & {$[75]$} \\
\hline 7E4B11 & & RPTPbeta & Glioblastoma & {$[76]$} \\
\hline $\operatorname{ch} 25 \mathrm{~A} 11$ & Chimeric & CDCP1 & Prostate carcinoma & {$[80]$} \\
\hline Cetuximab & & EGFR & Various & {$[94]$} \\
\hline hj591 & Humanized & PSMA & Prostate carcinoma & {$[85]$} \\
\hline Trastuzumab & & HER2 & Breast carcinoma & {$[95]$} \\
\hline $\mathrm{I} / \mathrm{F} 8$ & $\mathrm{scFv}$ & CD166 & Various & [88] \\
\hline
\end{tabular}

The studies, summarized in this review, indicate that saporin-S6-based ITs are extremely powerful in vitro and maintain good anti-tumor effectiveness in vivo. Clinical results have demonstrated the efficacy of ITs in cancer patients who are refractory to traditional modalities of treatment, including surgery, radiation therapy and chemotherapy. 
The IT specificity is based upon characteristics (surface antigens) that are completely independent from the parameters determining the toxicity of chemo- and radiotherapy. This difference allows for a non-superimposition of side effects and for unimpaired cytotoxicity toward cell clones that are resistant to chemo- and radiotherapy.

The large number of patents protecting immunoconjugates or their components indicates the fervid interest in the field by institutional researchers and pharmaceutical companies. We and many other investigators are confident that in the near future, immunoconjugates could have an important role in cancer treatment [9]. The greater than twenty antibody-drug conjugates and the eight ITs in clinical trials demonstrate the maturity of this approach [102]. A good example is represented by the anti-HER2 conjugate T-DM1 (trastuzumab emtansine), recently (February 2013) approved by the US FDA for patients with HER2-positive, late-stage breast cancer [102].

In the last years many clinical trials have been conducted with ITs, prevalently containing deglycosylated A chain of ricin, truncated diphtheria toxin or Pseudomonas exotoxin A [102]. RIP containing ITs present some advantages over those containing bacterial toxins, they lack the natural immunization often present against bacterial proteins and are numerous and often not immunologically related. The availability of different toxic proteins, together with the recent progresses in the production of non-immunogenic Abs (humanized mAbs or scFvs) could be useful to bypass the immunogenicity problem by sequential administration of ITs containing different non-cross reacting RIPs.

\section{Acknowledgments}

This study was supported by the University of Bologna with funds for selected research topics and by Pallotti's Legacy for Cancer Research.

\section{Conflicts of Interest}

The authors declare no conflict of interest.

\section{References}

1. Stirpe, F.; Battelli, M.G. Ribosome-inactivating proteins: Progress and problems. Cell Mol. Life Sci. 2006, 63, 1850-1866.

2. Barbieri, L.; Valbonesi, P.; Bonora, E.; Gorini, P.; Bolognesi, A.; Stirpe, F. Polynucleotide: Adenosine glycosidase activity of ribosome-inactivating proteins: Effect on DNA, RNA and poly(A). Nucleic Acids Res. 1997, 25, 518-522.

3. Bolognesi, A.; Polito, L.; Lubelli, C.; Barbieri, L.; Parente, A.; Stirpe, F. Ribosome-inactivating and adenine polynucleotide glycosylase activities in Mirabilis jalapa L. tissues. J. Biol. Chem. 2002, 277, 13709-13716.

4. Barbieri, L.; Brigotti, M.; Perocco, P.; Carnicelli, D.; Ciani, M.; Mercatali, L.; Stirpe, F. Ribosome-inactivating proteins depurinate poly(ADP-ribosyl)ated poly(ADP-ribose) polymerase and have transforming activity for 3 T3 fibroblasts. FEBS Lett. 2003, 538, 178-182. 
5. Puri, M.; Kaur, I.; Perugini, M.A.; Gupta, R.C. Ribosome-inactivating proteins: Current status and biomedical applications. Drug Discov. Today 2012, 17, 774-783.

6. Ferreras, J.M.; Citores, L.; Iglesias, R.; Jiménez, P.; Girbés, T. Use of ribosome-inactivating proteins from Sambucus. for the construction of immunotoxins and conjugates for cancer therapy. Toxins 2011, 3, 420-441.

7. Battelli, M.G. Cytotoxicity and toxicity to animals and humans of ribosome-inactivating proteins. Mini Rev. Med. Chem. 2004, 4, 513-521.

8. Stirpe, F. Ribosome-inactivating proteins: From toxins to useful proteins. Toxicon 2013, 67, 12-16.

9. FitzGerald, D.J.; Wayne, A.S.; Kreitman, R.J.; Pastan, I. Treatment of hematologic malignancies with immunotoxins and antibody-drug conjugates. Cancer Res. 2011, 71, 6300-6309.

10. Kawakami, K.; Nakajima, O.; Morishita, R.; Nagai, R. Targeted anticancer immunotoxins and cytotoxic agents with direct killing moieties. Sci. World J. 2006, 6, 781-790.

11. Bolognesi, A.; Polito, L. Immunotoxins and other conjugates: Pre-clinical studies. Mini Rev. Med. Chem. 2004, 4, 563-583.

12. Polito, L.; Bortolotti, M.; Pedrazzi, M.; Bolognesi, A. Immunotoxins and other conjugates containing saporin-S6 for cancer therapy. Toxins 2011, 3, 697-720.

13. Stirpe, F.; Gasperi-Campani, A.; Barbieri, L.; Falasca, A.; Abbondanza, A.; Stevens, W.A. Ribosome-inactivating proteins from the seeds of Saponaria officinalis L. (soapwort), of Agrostemma. githago L. (corn cockle) and of Asparagus officinalis L. (asparagus), and from the latex of Hura.crepitans L. (sandbox tree). Biochem. J. 1983, 216, 617-625.

14. Ferreras, J.M.; Barbieri, L.; Girbés, T.; Battelli, M.G.; Rojo, M.A.; Arias, F.J.; Rocher, M.A.; Soriano, F.; Mendéz, E.; Stirpe, F. Distribution and properties of major ribosome-inactivating proteins (28 S rRNA $N$-glycosidases) of the plant Saponaria officinalis L. (Caryophyllaceae). Biochim. Biophys. Acta 1993, 1216, 31-42.

15. Maras, B.; Ippoliti, R.; De Luca, E.; Lendaro, E.; Bellelli, A.; Barra, D.; Bossa, F.; Brunori, M. The amino acid sequence of a ribosome-inactivating protein from Saponaria officinalis seeds. Biochem. Int. 1990, 21, 831-838.

16. Barra, D.; Maras, B.; Schininà, M.E.; Angelaccio, S.; Bossa, F. Assessment of sequence features in internal regions of proteins. Biotechnol. Appl. Biochem. 1991, 13, 48-53.

17. Savino, C.; Federici, L.; Brancaccio, A.; Ippoliti, R.; Lendaro, E.; Tsernoglou, D. Crystallization and preliminary X-ray study of saporin, a ribosome-inactivating protein from Saponaria officinalis. Acta Crystallogr. Sect. D 1998, 54, 636-638.

18. Savino, C.; Federici, L.; Ippoliti, R.; Lendaro, E.; Tsernoglou, D. The crystal structure of saporin SO6 from Saponaria officinalis and its interaction with the ribosome. FEBS Lett. 2000, 470, 239-243.

19. De Virgilio, M.; Lombardi, A.; Caliandro, R.; Fabbrini, M.S. Ribosome-inactivating proteins: From plant defense to tumor attack. Toxins 2010, 2, 2699-2737.

20. Fermani, S.; Tosi, G.; Farini, V.; Polito, L.; Falini, G.; Ripamonti, A.; Barbieri, L.; Chambery, A.; Bolognesi, A. Structure/function studies on two type 1 ribosome inactivating proteins: Bouganin and lychnin. J. Struct. Biol. 2009, 168, 278-287.

21. Ghosh, P.; Batra, J.K. The differential catalytic activity of ribosome-inactivating proteins saporin 5 and 6 is due to a single substitution at position 162. Biochem. J. 2006, 400, 99-104. 
22. Fermani, S.; Falini, G.; Ripamonti, A.; Polito, L.; Stirpe, F.; Bolognesi, A. The 1.4 anstroms structure of dianthin 30 indicates a role of surface potential at the active site of type 1 ribosome inactivating proteins. J. Struct. Biol. 2005, 149, 204-212.

23. Santanché, S.; Bellelli, A.; Brunori, M. The unusual stability of saporin, a candidate for the synthesis of immunotoxins. Biochem. Biophys. Res. Commun. 1997, 234, 129-132.

24. Bolognesi, A.; Tazzari, P.L.; Tassi, C.; Gromo, G.; Gobbi, M.; Stirpe, F. A comparison of anti-lymphocyte immunotoxins containing different ribosome-inactivating proteins and antibodies. Clin. Exp. Immunol. 1992, 89, 341-346.

25. Colaço, M.; Bapat, M.M.; Misquith, S.; Jadot, M.; Wattiaux-De Coninck, S.; Wattiaux, R. Uptake and intracellular fate of gelonin, a ribosome-inactivating protein, in rat liver. Biochem. Biophys. Res. Commun. 2002, 296, 1180-1185.

26. Battelli, M.G.; Montacuti, V.; Stirpe, F. High sensitivity of cultured human trophoblasts to ribosome-inactivating proteins. Exp. Cell Res. 1992, 201, 109-112.

27. Cavallaro, U.; Nykjaer, A.; Nielsen, M.; Soria, M.R. Alpha 2-macroglobulin receptor mediates binding and cytotoxicity of plant ribosome-inactivating proteins. Eur. J. Biochem. 1995, 232, $165-171$.

28. Bagga, S.; Hosur, M.V.; Batra, J.K. Cytotoxicity of ribosome-inactivating protein saporin is not mediated through alpha2-macroglobulin receptor. FEBS Lett. 2003, 541, 16-20.

29. Bolognesi, A.; Polito, L.; Scicchitano, V.; Orrico, C.; Pasquinelli, G.; Musiani, S.; Santi, S.; Riccio, M.; Bortolotti, M.; Battelli, M.G. Endocytosis and intracellular localisation of type 1 ribosome-inactivating protein saporin-s6. J. Biol. Regul. Homeost. Agents 2012, 26, 97-109.

30. Wesche, J.; Rapak, A.; Olsnes, S. Dependence of ricin toxicity on translocation of the toxin A-chain from the endoplasmic reticulum to the cytosol. J. Biol. Chem. 1999, 274, 34443-34449.

31. Vago, R.; Marsden, C.J.; Lord, J.M.; Ippoliti, R.; Flavell, D.J.; Flavell, S.U.; Ceriotti, A.; Fabbrini, M.S. Saporin and ricin A chain follow different intracellular routes to enter the cytosol of intoxicated cells. FEBS J. 2005, 272, 4983-4995.

32. Battelli, M.G.; Bolognesi, A.; Olivieri, F.; Polito, L.; Stirpe, F. Different sensitivity of CD30 cell lines to Ber-H2/saporin-S6 immunotoxin. J. Drug Target. 1998, 5, 181-91.

33. Ippoliti, R.; Ginobbi, P.; Lendaro, E.; D’Agostino, I.; Ombres, D.; Benedetti, P.A.; Brunori, M.; Citro, G. The effect of monensin and chloroquine on the endocytosis and toxicity of chimeric toxins. Cell Mol. Life Sci. 1998, 54, 866-875.

34. Daniels-Wells, T.R.; Helguera, G.; Rodríguez, J.A.; Leoh, L.S.; Erb, M.A.; Diamante, G.; Casero, D.; Pellegrini, M.; Martínez-Maza, O.; Penichet, M.L. Insights into the mechanism of cell death induced by saporin delivered into cancer cells by an antibody fusion protein targeting the transferrin receptor 1. Toxicol. in Vitro 2013, 27, 220-231.

35. Battelli, M.G.; Barbieri, L.; Stirpe, F. Toxicity of, and histological lesions caused by, ribosome-inactivating proteins, their IgG-conjugates, and their homopolymers. APMIS 1990, 98, $585-593$.

36. Barbieri, L.; Battelli, M.G.; Stirpe, F. Ribosome-inactivating proteins from plants. Biochim. Biophys. Acta 1993, 1154, 237-282. 
37. Bergamaschi, G.; Perfetti, V.; Tonon, L.; Novella, A.; Lucotti, C.; Danova, M.; Glennie, M.J.; Merlini, G.; Cazzola, M. Saporin, a ribosome-inactivating protein used to prepare immunotoxins, induces cell death via apoptosis. Br. J. Haematol. 1996, 93, 789-794.

38. Bolognesi, A.; Tazzari, P.L.; Olivieri, F.; Polito, L.; Falini, B.; Stirpe, F. Induction of apoptosis by ribosome-inactivating proteins and related immunotoxins. Int. J. Cancer 1996, 68, 349-355.

39. Sikriwal, D.; Ghosh, P.; Batra, J.K. Ribosome inactivating protein saporin induces apoptosis through mitochondrial cascade, independent of translation inhibition. Int. J. Biochem. Cell Biol. 2008, 40, 2880-2888.

40. Polito, L.; Bortolotti, M.; Farini, V.; Battelli, M.G.; Barbieri, L.; Bolognesi, A. Saporin induces multiple death pathways in lymphoma cells with different intensity and timing as compared to ricin. Int. J. Biochem. Cell Biol. 2009, 41, 1055-1061.

41. Cimini, A.; Mei, S.; Benedetti, E.; Laurenti, G.; Koutris, I.; Cinque, B.; Cifone, M.G.; Galzio, R.; Pitari, G.; Di Leandro, L.; et al. Distinct cellular responses induced by saporin and a transferrin-saporin conjugate in two different human glioblastoma cell lines. J. Cell Physiol. 2012, 227, 939-951.

42. Bagga, S.; Seth, D.; Batra, J.K. The cytotoxic activity of ribosome-inactivating protein saporin-6 is attributed to its rRNA $N$-glycosidase and internucleosomal DNA fragmentation activities. $J$. Biol. Chem. 2003, 278, 4813-4820.

43. Galluzzi, L.; Vicencio, J.M.; Kepp, O.; Tasdemir, E.; Maiuri, M.C.; Kroemer, G. To die or not to die: That is the autophagic question. Curr. Mol. Med. 2008, 8, 78-91.

44. Madhumathi, J.; Verma, R.S. Therapeutic targets and recent advances in protein immunotoxins. Curr. Opin. Microbiol. 2012, 15, 300-309.

45. Fracasso, G.; Stirpe, F.; Colombatti, M. Ribosome-Inactivating Protein-Containing Conjugates for Therapeutic Use. In Toxic Plant Proteins, Plant Cell Monographs; Lord, J.M., Hartley, R.M., Eds.; Springer-Verlag: Heidelberg, Berlin, German, 2010; pp. 225-263.

46. Frankel, A.E.; Kreitman, R.J.; Sausville, E.A. Targeted toxins. Clin. Cancer Res. 2000, 6, 326-334.

47. Liu, X.Y.; Pop, L.M.; Schindler, J.; Vitetta, E.S. Immunotoxins constructed with chimeric, short-lived anti-CD22 monoclonal antibodies induce less vascular leak without loss of cytotoxicity. MAbs 2012, 4, 57-68.

48. Benedetti, G.; Bondesan, P.; Caracciolo, D.; Cherasco, C.; Ruggieri, D.; Gastaldi, M.E.; Pileri, A.; Gianni, A.M.; Tarella, C. Selection and characterization of early hematopoietic progenitors using an anti-CD71/S06 immunotoxin. Exp. Hematol. 1994, 22, 166-173.

49. Bolognesi, A.; Polito, L.; Tazzari, P.L.; Lemoli, R.M.; Lubelli, C.; Fogli, M.; Boon, L.; De Boer, M.; Stirpe, F. In vitro anti-tumour activity of anti-CD80 and anti-CD86 immunotoxins containing type 1 ribosome-inactivating proteins. Br. J. Haematol. 2000, 110, 351-361.

50. Wiley, R.G. Substance P receptor-expressing dorsal horn neurons: Lessons from the targeted cytotoxin, substance P-saporin. Pain 2008, 136, 7-10.

51. Ricceri, L. Behavioral patterns under cholinergic control during development: Lessons learned from the selective immunotoxin 192 IgG saporin. Neurosci. Biobehav. Rev. 2003, 27, 377-384.

52. Wang, D.; Li, Q.; Hudson, W.; Berven, E.; Uckun, F.; Kersey, J.H. Generation and characterization of an anti-CD19 single-chain Fv immunotoxin composed of $C$-terminal disulfide-linked dgRTA. Bioconjug. Chem. 1997, 8, 878-884. 
53. Lombardi, A.; Bursomanno, S.; Lopardo, T.; Traini, R.; Colombatti, M.; Ippoliti, R.; Flavell, D.J.; Flavell, S.U.; Ceriotti, A.; Fabbrini, M.S. Pichia. pastoris as a host for secretion of toxic saporin chimeras. FASEB J. 2010, 24, 253-265.

54. Mayfield, S. Production of anti-cancer immunotoxins in algae: Ribosome inactivating proteins as fusion partners. Biotechnol. Bioeng. 2013, 110, 2826-2835.

55. Chaudhary, V.K.; Gallo, M.G.; FitzGerald, D.J.; Pastan, I. A recombinant single-chain immunotoxin composed of anti-Tac variable regions and a truncated diphtheria toxin. Proc. Natl. Acad. Sci. USA 1990, 87, 9491-9494.

56. Thorpe, P.E.; Brown, A.N.; Bremner, J.A., Jr.; Foxwell, B.M.; Stirpe, F. An immunotoxin composed of monoclonal anti-Thy 1.1 antibody and a ribosome-inactivating protein from Saponaria officinalis: Potent antitumor effects in vitro and in vivo. J. Natl. Cancer Inst. 1985, 75, 151-159.

57. Siena, S.; Bregni, M.; Formosa, A.; Brando, B.; Marenco, P.; Lappi, D.A.; Bonadonna, G.; Gianni, A.M. Immunotoxin-mediated inhibition of chronic lymphocytic leukemia cell proliferation in humans. Cancer Res. 1989, 49, 3328-3332.

58. Tazzari, P.L.; Bolognesi, A.; De Totero, D.; Lemoli, R.M.; Fortuna, A.; Conte, R.; Crumpton, M.J.; Stirpe, F. Immunotoxins containing saporin linked to different CD2 monoclonal antibodies: In vitro evaluation. Br. J. Haematol. 1994, 86, 97-105.

59. Morland, B.J.; Barley, J.; Boehm, D.; Flavell, S.U.; Ghaleb, N.; Kohler, J.A.; Okayama, K.; Wilkins, B.; Flavell, D.J. Effectiveness of HB2 (anti-CD7) - Saporin immunotoxin in an in vivo model of human T-cell leukaemia developed in severe combined immunodeficient mice. Br. $J$. Cancer 1994, 69, 279-285.

60. Flavell, D.J.; Warnes, S.; Noss, A.; Flavell, S.U. Host-mediated antibody-dependent cellular cytotoxicity contributes to the in vivo therapeutic efficacy of an anti-CD7-saporin immunotoxin in a severe combined immunodeficient mouse model of human T-cell acute lymphoblastic leukemia. Cancer Res. 1998, 58, 5787-5794.

61. Flavell, D.J.; Warnes, S.L.; Noss, A.L.; Flavell, S.U. Anti-CD7 antibody and immunotoxin treatment of human $\mathrm{CD} 7(+) \mathrm{T}$-cell leukaemia is significantly less effective in NOD/LtSz-scid mice than in CB.17 scid mice. Br. J. Cancer 2000, 83, 1755-1761.

62. Flavell, D.J.; Boehm, D.A.; Okayama, K.; Kohler, J.A.; Flavell, S.U. Therapy of human T-cell acute lymphoblastic leukaemia in severe combined immunodeficient mice with two different anti-CD7-saporin immunotoxins containing hindered or non-hindered disulphide cross-linkers. Int. J. Cancer 1994, 58, 407-414.

63. Flavell, D.J.; Boehm, D.A.; Noss, A.; Flavell, S.U. Comparison of the potency and therapeutic efficacy of the anti-CD7 immunotoxin HB2-saporin constructed with one or two saporin moieties per immunotoxin molecule. Br. J. Cancer 1997, 75, 1035-1043.

64. Flavell, D.J.; Flavell, S.U.; Boehm, D.; Emery, L.; Noss, A.; Ling, N.R.; Richardson, P.R.; Hardie, D.; Wright, D.H. Preclinical studies with the anti-CD19-saporin immunotoxin BU12-SAPORIN for the treatment of human-B-cell tumours. Br. J. Cancer 1995, 72, 1373-1379. 
65. Bolognesi, A.; Tazzari, P.L.; Olivieri, F.; Polito, L.; Lemoli, R.; Terenzi, A.; Pasqualucci, L.; Falini, B.; Stirpe, F. Evaluation of immunotoxins containing single-chain ribosome-inactivating proteins and an anti-CD22 monoclonal antibody (OM124): In vitro and in vivo studies. Br. J. Haematol. 1998, 101, 179-188.

66. Bolognesi, A.; Polito, L.; Farini, V.; Bortolotti, M.; Tazzari, P.L.; Ratta, M.; Ravaioli, A.; Horenstein, A.L.; Stirpe, F.; Battelli, M.G.; Malavasi, F. CD38 as a target of IB4 mAb carrying saporin-S6: Design of an immunotoxin for ex vivo depletion of hematological CD38 ${ }^{+}$neoplasia. J. Biol. Regul. Homeost. Agents 2005, 19, 145-152.

67. Vooijs, W.C.; Otten, H.G.; Van Vliet, M.; Van Dijk, A.J.; De Weger, R.A.; De Boer, M.; Bohlen, H.; Bolognesi, A.; Polito, L.; De Gast, G.C. B7-1 (CD80) as target for immunotoxin therapy for Hodgkin's disease. Br. J. Cancer 1997, 76, 1163-1169.

68. Vooijs, W.C.; Post, J.; Wijdenes, J.; Schuurman, H.J.; Bolognesi, A.; Polito, L.; Stirpe, F.; Bast, E.J.; De Gast, G.C. Efficacy and toxicity of plasma-cell-reactive monoclonal antibodies B-B2 and B-B4 and their immunotoxins. Cancer Immunol. Immunother. 1996, 42, 319-328.

69. Tazzari, P.L.; Bolognesi, A.; De Totero, D.; Falini, B.; Lemoli, R.M.; Soria, M.R.; Pileri, S.; Gobbi, M.; Stein, H.; Flenghi, L.; et al. Ber-H2 (anti-CD30)-saporin immunotoxin: A new tool for the treatment of Hodgkin's disease and $\mathrm{CD}^{+} 0^{+}$lymphoma: In vitro evaluation. $\mathrm{Br}$. J. Haematol. 1992, 81, 203-211.

70. Pasqualucci, L.; Wasik, M.; Teicher, B.A.; Flenghi, L.; Bolognesi, A.; Polito, L.; Stirpe, F.; Falini, B.; Kadin, M.E. Antitumor activity of anti-CD30 immunotoxin (Ber-H2/saporin) in vitro and in severe combined immunodeficiency disease mice xenografted with human CD30 anaplastic large-cell lymphoma. Blood 1995, 85, 2139-2146.

71. Tazzari, P.L.; De Totero, D.; Bolognesi, A.; Testoni, N.; Pileri, S.; Roncella, S.; Reato, G.; Stein, H.; Gobbi, M.; Stirpe, F. An Epstein-Barr virus-infected lymphoblastoid cell line (D430B) that grows in SCID-mice with the morphologic features of a $\mathrm{CD}^{+} 0^{+}$anaplastic large cell lymphoma, and is sensitive to anti-CD30 immunotoxins. Haematologica 1999, 84, 988-995.

72. Polito, L.; Bortolotti, M.; Farini, V.; Pedrazzi, M.; Tazzari, P.L.; Bolognesi, A. ATG-saporin-S6 immunotoxin: A new potent and selective drug to eliminate activated lymphocytes and lymphoma cells. Br. J. Haematol. 2009, 147, 710-718.

73. Tecce, R.; Nicotra, M.R.; Fraioli, R.; Cuomo, M.; Trizio, D.; Natali, P.G. Saporin 6 conjugated to monoclonal antibody selectively kills human melanoma cells. Melanoma Res. 1991, 1, 115-123.

74. Battelli, M.G.; Polito, L.; Bolognesi, A.; Lafleur, L.; Fradet, Y.; Stirpe, F. Toxicity of ribosome-inactivating proteins-containing immunotoxins to a human bladder carcinoma cell line. Int. J. Cancer 1996, 65, 485-490.

75. Gosselaar, P.H.; Van-Dijk, A.J.; De-Gast, G.C.; Polito, L.; Bolognesi, A.; Vooijs, W.C.; Verheul, A.F.; Krouwer, H.G.; Marx, J.J. Transferrin toxin but not transferrin receptor immunotoxin is influenced by free transferrin and iron saturation. Eur. J. Clin. Invest. 2002, 32, 61-69.

76. Foehr, E.D.; Lorente, G.; Kuo, J.; Ram, R.; Nikolich, K.; Urfer, R. Targeting of the receptor protein tyrosine phosphatase beta with a monoclonal antibody delays tumor growth in a glioblastoma model. Cancer Res. 2006, 66, 2271-2278. 
77. Polito, L.; Mancuso, R.; Mercatelli, D.; Bortolotti, M.; Bolognesi, A. Monoclonal Antibodies Targeting CD20 and Other Lymphocyte CD Markers in Lymphoma Treatment. In Monoclonal Antibodies in Oncology; Uckun, F.M., Ed.; Future Medicine: London, UK, 2013; pp. 6-19.

78. Polito, L.; Bolognesi, A.; Tazzari, P.L.; Farini, V.; Lubelli, C.; Zinzani, P.L.; Ricci, F.; Stirpe, F. The conjugate Rituximab/SAP-S6 completely inhibits clonogenic growth of CD20-expressing cells and produces a synergistic toxic effect with Fludarabine. Leukemia 2004, 18, 1215-1222.

79. Daniels, T.R.; Ng, P.P.; Delgado, T.; Lynch, M.R.; Schiller, G.; Helguera, G.; Penichet, M.L. Conjugation of an anti transferrin receptor IgG3-avidin fusion protein with biotinylated saporin results in significant enhancement of its cytotoxicity against malignant hematopoietic cells. Mol. Cancer Ther. 2007, 6, 2995-3008.

80. Siva, A.C.; Wild, M.A.; Kirkland, R.E.; Nolan, M.J.; Lin, B.; Maruyama, T.; Yantiri-Wernimont, F.; Frederickson, S.; Bowdish, K.S.; Xin, H. Targeting CUB domain-containing protein 1 with a monoclonal antibody inhibits metastasis in a prostate cancer model. Cancer Res. 2008, 68, 3759-3766.

81. Bortolotti, M.; Polito, L.; Farini, V.; Pedrazzi, M.; Battelli, M.G.; Bolognesi, A. Anti-tumor activity of Epratuzumab/saporin-S6. Amer J. Pathol. 2012, 181, S17.

82. Bortolotti, M.; Polito, L.; Farini, V.; Bolognesi, A. Epratuzumab/Saporin-S6: An anti-CD22 immunotoxin for selective depletion of B-cells neoplasms. Haematologica 2010, 95, S86.

83. Kato, J.; O’Donnell, R.T.; Abuhay, M.; Tuscano, J.M. Efficacy and toxicity of a CD22-targeted antibody-saporin conjugate in a xenograft model of non-Hodgkin's lymphoma. Oncoimmunology 2012, 1, 1469-1475.

84. Kato, J.; Satake, N.; O’Donnell, R.T.; Abuhay, M.; Lewis, C.; Tuscano, J.M. Efficacy of a CD22-targeted antibody-saporin conjugate in a xenograft model of precursor-B cell acute lymphoblastic leukemia. Leuk. Res. 2013, 37, 83-88.

85. Kuroda, K.; Liu, H.; Kim, S.; Guo, M.; Navarro, V.; Bander, N.H. SAP toxin-conjugated monoclonal antibody targeting prostate-specific membrane antigen has potent anticancer activity. Prostate 2010, 70, 1286-1294.

86. Tazzari, P.L.; Polito, L.; Bolognesi, A.; Pistillo, M.P.; Capanni, P.; Palmisano, G.L.; Lemoli, R.M.; Curti, A.; Biancone, L.; Camussi, G.; et al. Immunotoxins containing recombinant anti-CTLA-4 single-chain fragment variable antibodies and saporin: In vitro results and in vivo effects in an acute rejection model. J. Immunol. 2001, 167, 4222-4229.

87. Pistillo, M.P.; Tazzari, P.L.; Palmisano, G.L.; Pierri, I.; Bolognesi, A.; Ferlito, F.; Capanni, P.; Polito, L.; Ratta, M.; Pileri, S.; et al. CTLA-4 is not restricted to the lymphoid cell lineage and can function as a target molecule for apoptosis induction of leukemic cells. Blood 2003, 101, 202-209.

88. Piazza, T.; Cha, E.; Bongarzone, I.; Canevari, S.; Bolognesi, A.; Polito, L.; Bargellesi, A.; Sassi, F.; Ferrini, S.; Fabbi, M. Internalization and recycling of ALCAM/CD166 detected by a fully human single-chain recombinant antibody. J. Cell Sci. 2005, 118, 1515-1525.

89. Falini, B.; Bolognesi, A.; Flenghi, L.; Tazzari, P.L.; Broe, M.K.; Stein, H.; Dürkop, H.; Aversa, F.; Corneli, P.; Pizzolo, G.; et al. Response of refractory Hodgkin's disease to monoclonal anti-CD30 immunotoxin. Lancet 1992, 339, 1195-1196. 
90. Pasqualucci, L.; Flenghi, L.; Terenzi, A.; Bolognesi, A.; Stirpe, F.; Bigerna, B.; Falini, B. Immunotoxin therapy of hematological malignancies. Haematologica 1995, 80, 546-556.

91. Bonardi, M.A.; Bell, A.; French, R.R.; Gromo, G.; Hamblin, T.; Modena, D.; Tutt, A.L.; Glennie, M.J. Initial experience in treating human lymphoma with a combination of bispecific antibody and saporin. Int. J. Cancer Suppl. 1992, 7, 73-77.

92. French, R.R.; Hamblin, T.J.; Bell, A.J.; Tutt, A.L.; Glennie, M.J. Treatment of B-cell lymphomas with combination of bispecific antibodies and saporin. Lancet 1995, 346, 223-224.

93. French, R.R.; Bell, A.J.; Hamblin, T.J.; Tutt, A.L.; Glennie, M.J. Response of B-cell lymphoma to a combination of bispecific antibodies and saporin. Leuk. Res. 1996, 20, 607-617.

94. Yip, W.L.; Weyergang, A.; Berg, K.; Tønnesen, H.H.; Selbo, P.K. Targeted delivery and enhanced cytotoxicity of cetuximab-saporin by photochemical internalization in EGFR-positive cancer cells. Mol. Pharm. 2007, 4, 241-251.

95. Berstad, M.B.; Weyergang, A.; Berg, K. Photochemical internalization (PCI) of HER2-targeted toxins: Synergy is dependent on the treatment sequence. Biochim. Biophys. Acta 2012, 1820, 1849-1858.

96. Bostad, M.; Berg, K.; Høgset, A.; Skarpen, E.; Stenmark, H.; Selbo, P.K. Photochemical internalization (PCI) of immunotoxins targeting CD133 is specific and highly potent at femtomolar levels in cells with cancer stem cell properties. J. Control. Release 2013, 168, 317-326.

97. Stratford, E.W.; Bostad, M.; Castro, R.; Skarpen, E.; Berg, K.; Høgset, A.; Myklebost, O.; Selbo, P.K. Photochemical internalization of CD133-targeting immunotoxins efficiently depletes sarcoma cells with stem-like properties and reduces tumorigenicity. Biochim. Biophys. Acta 2013, 1830, 4235-4243.

98. Weng, A.; Bachran, C.; Fuchs, H.; Krause, E.; Stephanowitz, H.; Melzig, M.F. Enhancement of saporin cytotoxicity by Gypsophila saponins - more than stimulation of endocytosis. Chem. Biol. Interact. 2009, 181, 424-429.

99. Bachran, C.; Drywa, G.; Dürkop, H.; Sutherland, M.; Bachran, D.; Müller, C.; Weng, A.; Melzig, M.F.; Fuchs, H. Inhibition of tumor growth by targeted toxins in mice is dramatically improved by Saponinum album in a synergistic way. J. Immunother. 2009, 32, 713-725.

100. Thakur, M.; Mergel, K.; Wenig, A.; von Mallinckrodt, B.; Gilabert-Oriol, R.; Dürkop, H.; Melzig, M.F.; Fuchs, H. Targeted tumor therapy by epidermal growth factor appended toxin and purified saponin: An evaluation of toxicity and therapeutic potential in syngeneic tumor bearing mice. Mol. Oncol. 2013, 7, 475-483.

101. Fretz, M.M.; Høgset, A.; Koning, G.A.; Jiskoot, W.; Storm, G. Cytosolic delivery of liposomally targeted proteins induced by photochemical internalization. Pharm. Res. 2007, 24, 2040-2047.

102. Dosio, F.; Stella, B.; Cerioni, S.; Gastaldi, D.; Arpicco, S. Advances in anticancer antibody-drug conjugates and immunotoxins. Recent Pat. Anticancer Drug Discov. 2013, epub ahead of print.

(C) 2013 by the authors; licensee MDPI, Basel, Switzerland. This article is an open access article distributed under the terms and conditions of the Creative Commons Attribution license (http://creativecommons.org/licenses/by/3.0/). 